\title{
PENERAPAN NON-LINIER SUPPORT VECTOR MACHINE PADA PENGGUNAAN ALAT KONTRASEPSI DI PROVINSI MALUKU UTARA
}

\author{
Muhamad Budiman Johra \\ Universitas Padjadjaran, muhamad.budiman@bps.go.id
}

DOI:https://doi.org/10.15642/mantik.2018.4.2.137-142

\begin{abstract}
Abstrak
Sasaran Strategis dari Badan Kependudukan dan Keluarga Berencana Nasional (BKKBN) adalah menurunkan laju pertumbuhan penduduk karena laju pertumbuhan penduduk yang tinggi menyebabkan kuantitas penduduk yang tinggi pula. Menurut Departemen Kesehatan (2013) perempuan kawin usia 15-49 tahun yang tidak ber-KB sebagian besar di wilayah Indonesia Timur yang salah satunya Maluku Utara. Menurut BKKBN Provinsi Maluku Utara, angka kelahiran meningkat dari 57,4 menjadi 57,9. Hal ini terjadi karena banyak peserta KB yang mengalami ketidakberlangsungan (drop out), kegagalan dan efek samping alat kontrasepsi, kebutuhan ber-KB yang tidak terlayani yakni 9,1 pada 2007 menjadi 8,5 pada 2012 dengan target 5 pada 2014. Sehingga penting untuk mengetahui faktor determinan yang mempengaruhi wanita untuk menggunakan alat kontrasepsi. Terdapat beberapa metode dalam klasifikasi, salah satunya adalah Support Vector Machine (SVM). SVM memiliki kelebihan dibanding metode klasifikasi lainnya karena Support Vector Machine tidak hanya meminimalkan error pada trainset, tetapi juga memiliki kemampuan generalisasi yang tinggi. Hal ini tercermin pada pemilihan margin yang maksimal. Penelitian ini menunjukkan Support Vector Machine dapat menggambarkan keputusan wanita usia subur untuk menggunakan alat kontrasepsi atau tidak. Kernel terbaik pada penelitian ini adalah kernel radial basis dengan cost 1 dan gamma 0.14286
\end{abstract}

Kata kunci: Nonlinier Support Vector Machine, Alat Kontrasepsi, Kernel Trick, Apparent Error Rate

\begin{abstract}
The objective of BKKBN is to reduce the rate of population growth because the high population growth rate causes a high population quantity as well. According to the Departemen Kesehatan RI (2013), married women aged 15-49 years who don't use contraception mostly in eastern Indonesia, one of them is Provinsi Maluku Utara. According to BKKBN Provinsi Maluku Utara, the birth rate increased from 57.4 to 57.9. This happens because many KB participants are drop out, contraceptive failure and side effects, the need for family planning is served 9.1 in 2007 to 8.5 in 2012 with a target of 5 in 2014. Therefore, it important to know determinant factors that affect women to use contraceptives. There are several methods in the classification, one of which is the Support Vector Machine (SVM). SVM has advantages over other classification methods because the Support Vector Machine not only minimizes errors in the train set but also has a high generalization capability. This is reflected in maximal margin selection. This study shows the Support Vector Machine can describe the decision of women to use contraception or not. The best kernel in this study is a radial base kernel with cost 1 and gamma 0.14286 .
\end{abstract}

Keywords: Nonlinier Support Vector Contraceptive, Kernel Trick, Apparent Error Rate

\section{Pendahuluan}

Kereta api merupakan transportasi umum yang banyak digunakan oleh masyarakat baik dalam menunjang kegiatan sehari-hari terkait pekerjaan dan aktivitas harian lainnya yang bersifat rutin maupun sebagai solusi transportasi jarak jauh yang bersifat insidental. Kereta api sebagai transportasi umum memiliki beberapa keunggulan diantaranya memiliki waktu 
tempuh yang lebih dapat diprediksi karena terhindar dari kemacetan jalan raya dan juga mampu melayani penumpang yang jauh lebih banyak dalam sekali perjalanan dibandingkan dengan sarana transportasi umum darat lainnya.

Penjadwalan dan perencanaan kapasitas Kereta Api terkait erat dengan tingkat kepuasan penggunanya dan tingkat keuntungan usaha dari penyelenggara jasa layanan Kereta api tersebut. Lai dan Barkan [1] menyatakan bahwa manajemen kapasitas yang efektif merupakan kunci sukses dari penyelenggara jasa layanan Kereta api akan tetapi hal ini tidaklah mudah. Layanan Kereta api yang over-capacity akan membuat pengguna kecewa dan beralih pada moda transportasi lain selain itu juga membuat penyelenggara layanan Kereta api kehilangan potensi pendapatan dari para calon penumpang yang tidak tertampung. Di lain pihak, under-capacity akan membuat penyelenggara layanan Kereta api menanggung beban tambahan akibat gerbong yang tidak terisi. Oleh karena itu, diperlukan sebuah peramalan yang cukup tepat dalam memperkirakan jumlah penumpang Kereta api sehingga dapat dilakukan penyesuaian kapasitas layanan sesuai kebutuhan.

Back-propagation Neural Network (BPNN) merupakan teknik klasifikasi dan peramalan yang paling populer menggunakan supervised learning neural network. Akan tetapi, menurut Chen dan Su [2], teknik BPNN terbilang lambat konvergensinya dan memiliki tendensi dapat terjebak dalam lokal minima. Di lain pihak, menurut Riedmiller (1993) dalam [2] Resilient Back-propagation (Rprop) merupakan teknik yang memiliki konvergensi cepat dan masih menjaga akurasinya.

Penelitian ini bertujuan untuk melakukan peramalan penumpang Kereta api menggunakan teknik Rprop sehingga dapat dilakukan penyesuaian kapasitas layanan sesuai kebutuhan dengan harapan dapat meningkatkan kepuasan pengguna layanan sekaligus tingkat keuntungan dari penyelenggara jasa layanan Kereta api.

\section{Tinjauan Pustaka \\ 2.1 Faktor Determinan Penggunaan Alat Kontrasepsi}

Faktor-faktor yang mempengaruhi pemilihan metode kontrasepsi adalah:

- Faktor pasangan: pengetahuan, umur, gaya hidup, frekuensi senggama, jumlah keluarga yang diinginkan, pengalaman dengan kontrasepsi lalu, sikap wanita, dan sikap kepriaan.

- Faktor kesehatan: satus kesehatan, riwayat haid, riwayat keluarga, pemeriksaan fisik, dan pemeriksaan panggul

- Faktor metode kontrasepsi: efektivitas, efek samping minor, kerugian, komplikasi-komplikasi yang potensial, dan biaya

Umur dalam hubungannya dengan pemakaian $\mathrm{KB}$ berperan sebagai faktor intrinsik. Umur secara umum berperan terhadap organ, struktur biokimia maupun hormonal terhadap tubuh seorang wanita yang secara tidak langsung mempengaruhi terhadap pemilihan terhadap pemilihan alat kontrasepsi.

Jaminan Kesehatan Masyarakat (Jamkesmas) adalah kebijakan yang sangat efektif untuk mewujudkan keadilan dan kesejahteraan rakyat dan meningkatkan aksesibilitas masyarakat miskin terhadap pelayanan kesehatan yang tersedia. Jamkesmas diharapkan dapat mempercepat pencapaian sasaran pembangunan kesehatan dan peningkatan derajat kesehatan yang optimal. Sasaran Jamkesmas adalah seluruh masyarakat miskin, sangat miskin, dan mendekati miskin yang diperkirakan jumlahnya mencapai 76,4 juta [4]. Sumber dana Jamkesmas adalah Anggaran Pendapatan dan Belanja Negara (APBN) Departemen Kesehatan. Dengan adanya Jamkesmas, keluarga miskin akan mendapatkan pelayanan KB secara cumacuma baik obat maupun alat kontrasepsi. Program ini dimaksudkan agar keluarga miskin tidak kesulitan dalam mengakses program KB, karena bila pertambahan penduduk tidak dapat dikendalikan, maka beban pembangunan akan bertambah. 
Menurut Bouge dalam Lucas (1990) menyatakan bahwa pendidikan menunjukkan pengaruh yang lebih kuat terhadap fertilitas daripada variabel lain [5]. Pendidikan merupakan salah satu faktor yang sangat menentukan pengetahuan dan persepsi seseorang terhadap pentingnya sesuatu hal, termasuk pentingnya keikutsertaan dalam KB. Ini disebabkan seseorang yang berpendidikan tinggi akan lebih luas pandangannya dan lebih mudah menerima ide dan tata cara kehidupan baru. Penelitian menunjukkan bahwa tingkat pendidikan yang dimiliki mempunyai pengaruh yang kuat pada perilaku reproduksi dan penggunaan alat kontrasepsi. Berdasarkan Survei Demografi dan Kesehatan Indonesia (SDKI) 2002-2003, pemakaian alat kontrasepsi meningkat sejalan dengan tingkat pendidikan. Sebesar $45 \%$ wanita yang tidak sekolah menggunakan cara kontrasepsi modern, sedangkan wanita berpendidikan menengah atau lebih tinggi yang menggunakan cara kontrasepsi modern sebanyak 58\%. Semakin tinggi tingkat pendidikan wanita maka akan sangat tinggi pula kesadaran.

\section{Metode Peneltian}

\subsection{Support Vector Machine (SVM)}

SVM adalah suatu teknik yang dikembangkan oleh Vapnik pada tahun 1995 untuk melakukan prediksi, baik dalam kasus klasifikasi maupun regresi. SVM termasuk dalam kelas supervised learning. Secara teoritisk SVM dikembangkan untuk masalah klasifikasi dengan dua kelas sebagai pemisah antara dua kelas pada input space [6].

Setiap data latih dinyatakan oleh $\left(x_{i}, y_{i}\right)$ dengan $\quad i=1,2, \ldots, N, \quad$ dan $\quad x_{i}=$ $\left\{x_{i 1}, x_{i 2}, \ldots, x_{i} q\right\}^{T}$ merupakan atribut set untuk data ke $i$. Untuk $y_{i} \in\{-1,+1\}$ menyatakan label kelas. Hyperplane klasifikasi linear SVM seperti pada gambar diatas dinotasikan sebagai

$$
w . x_{i}+b=0
$$

$w$ dan $b$ adalah parameter model $w \cdot x_{i}$ merupakan inner-product antara $w$ dan $x_{i}$

Data $x_{i}$ yang masuk ke dalam kelas -1 adalah data yang memnuhi pertidaksamaan

$$
\text { w. } x_{i}+b \leq-1
$$

Data $x_{i}$ yang masuk ke dalam kelas +1 adalah data yang memenuhi pertidaksamaan

w. $x_{i}+b \geq-1$

Persamaan diatas dapat digambarkan pada Gambar 1:

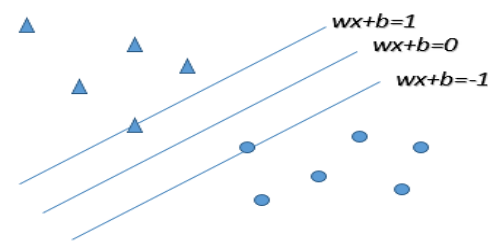

Gambar 1. Model Linier Support Vector Machine

Dengan mengurangkan persamaan (2) terhadap (3) akan didapatkan

$$
w\left(x_{b}-x_{a}\right)=2
$$

Dimana $x_{b}-x_{a}$ adalah vector paralel di posisi hyperplane. Margin hyperplane diberikan oleh jarak antara dua hyperplane dari dua kelas tersebut. Notasi diatas diringkas menjadi

$$
\|w\| x d=2 \text { atau } d=\frac{2}{\|w\|}
$$

\subsection{Hyperplane SVM}

Klasifikasi kelas data pada SVM pada persamaan (2) dan (3) dapat digabungkan dengan notasi :

$$
\begin{aligned}
& y_{i}\left(\boldsymbol{w} \cdot \boldsymbol{x}_{\boldsymbol{i}}+b\right) \geq 1, \quad i=1,2, \ldots, N(6) \\
& \quad \text { Margin optimal dihitung dengan }
\end{aligned}
$$
memaksimalkan jarak antara hyperplane dan data terdekat. Jarak ini dirumuskan dengan persamaan (3.10) ( $\|\boldsymbol{w}\|$ adalah vector bobot $w$ ). Selanjutnya masalah ini diformulasikan ke dalam problem Quadratic Programming (QP) dengan meminimalkan invers persamaan (3.10), $\frac{1}{2}\|\boldsymbol{w}\|^{2}$, di bawah konstrain (syarat), sebagai berikut:

Minimalkan:

$\frac{1}{2}\|\boldsymbol{w}\|^{2}$

Syarat.

$$
y_{i}\left(\boldsymbol{w} \cdot \boldsymbol{x}_{\boldsymbol{i}}+b\right) \geq 1, \quad i=1,2, \ldots, N
$$

Optimalisasi ini dapat diselesaikan dengan Lagrange multiplier:

$$
L_{p}=\frac{1}{2}\|\boldsymbol{w}\|^{2}-\sum_{i=1}^{N} \alpha_{i} \cdot y_{i}\left(\boldsymbol{w} \cdot \boldsymbol{x}_{\boldsymbol{i}}+b\right)
$$

$\alpha_{i}$ adalah Lagrange multiplier yang berkorespondensi dengan $x_{i}$. Nilai $\alpha_{i}$ adalah nol atau positif. Masalah optimasi di atas 
masih sulit diiselesaikan karena banyaknya parameter $\left(w, b\right.$ dan $\left.\alpha_{i}\right)$. Untuk menyederhanakannya, persamaan optimasi lagrange harus ditransformasi ke dalam fungsi Lagrange multiplier itu sendiri (disebut dualitas masalah).

Persamaan Lagrange multiplier (3.13) dapat dijabarkan menjadi:

$$
L_{p}=\frac{1}{2}\|\boldsymbol{w}\|^{2}-\left(\sum_{i=1}^{N} \alpha_{i} y_{i}\left(\boldsymbol{w} \cdot \boldsymbol{x}_{\boldsymbol{i}}\right)-\right.
$$
$\left.b \sum_{i=1}^{N} \alpha_{i} y_{i}+\sum_{i=1}^{N} \alpha_{i}\right)$

Syarat optimal ada dalam suku ketiga di ruas kanan dalam persamaan dan memaksa suku ini menjadi sama dengan 0. Dengan mengganti $w$ dan suku $\|w\|^{2}=\boldsymbol{w}_{\boldsymbol{i}} \cdot \boldsymbol{w}_{\boldsymbol{j}}$, maka persamaan di atas akan berubah menjadi dualitas Lagrange multiplier berupa $L_{d}$ dan didapatkan:

Maksimalkan:

$$
L_{d}=\sum_{i=1}^{N} \alpha_{i}-\frac{1}{2} \sum_{i, j} \alpha_{i} \alpha_{j} y_{i} y_{j} x_{i} x_{j}
$$

$\boldsymbol{x}_{\boldsymbol{i}} \boldsymbol{x}_{\boldsymbol{j}}$ merupakan dot-product dua data dalam data latih.

\subsection{Non-Linier Support Vector Machine}

Pada umumnya data dalam dunia nyata (real world) jarang yang bersifat linier separable, kebanyakan bersifat nonlinier. Untuk menyelesaikan problem non-linier, SVM dimodifikasi dengan memasukkan fungsi kernel. Dalam non-linier SVM [7] pertama-tama data $x$ dipetakan oleh fungsi $\Phi(x)$ ke ruang vector yang berdimensi lebih tinggi. Pada ruang vector yang baru ini, hyperplane yang memisahkan kedua class dapat dikonstruksikan.

Hal ini dapat digambarkan sebagai berikut:

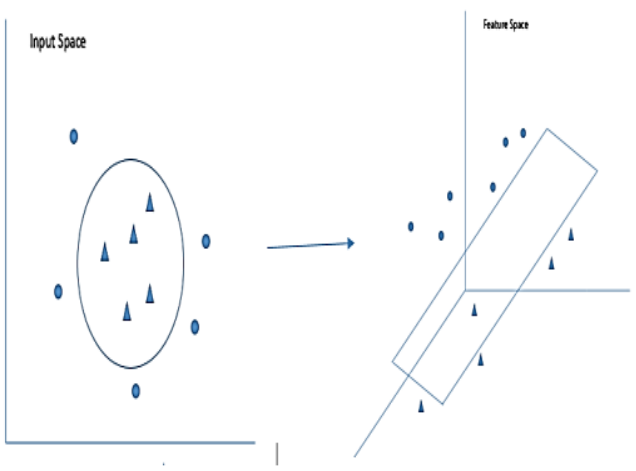

Gambar 2. Model Non-Linier Support Vector Machine
Pemetaan ini dilakukan dengan menjaga topologi data, dalam artian dua data yang berjarak dekat pada input space akan berjarak dekat juga pada feature space, sebaliknya dua data yang berjarak jauh pada input space juga akan berjarak jauh pada feature space.

Kernel trick memberikan berbagai kemudahan, karena dalam proses pembelajaran SVM, untuk menentukan support vector, kita hanya cukup mengetahui fungsi kernel yang dipakai dan tidak perlu mengetahui wujud dari fungsi nonlinier $\Phi$. Pada penelitian ini fungsi kernel yang akan dipakai adalah kernel Radial Basis, Polynomial, Linier dan Sigmoid.

\subsection{Kernel Trick}

Pada mulanya teknik machine learning dikembangkan dengan asumsi kelinearan, sehingga algoritma yang dihasilkan terbatas untuk kasus-kasus yang linear saja. Sedangkan untuk domain data secara real sangat jarang ditemukan data yang bersifat linier. Untuk menyelesaikan problem data yang tidak linier, SVM dapat dimodifikasi dengan memasukkan kernel trick. Kernel trick memberikan berbagai kemudahan, karena dalam proses pembelajaran SVM, untuk menentukan support vector, maka cukup dengan mengetahui fungsi kernel yang dipakai, dan tidak perlu mengetahui wujud dari fungsi non-linear.

Kita dapat memahami fungsi kernel dengan menggunakan aljabar pada composition rule. Yang menarik dari aljabar composition rule adalah kemudahan dalam memahami fungsi kernel pada feature space. Misalnya kita memiliki dua kernel yang valid yaitu $k_{a}$ dan $k_{b}$. Jika kita membentuk kernel baru dengan

$$
k(x, v)=k_{a}(x, v)+k_{b}(x, v)
$$

kernel akan menjadi valid.

\subsection{Sumber Data}

Data yang digunakan adalah data jumlah penumpang kereta api yang dikumpulkan oleh Badan Pusat Statistik dari PT Kereta Api Indonesia dan PT. KAI Commuter Jabodetabek. Periode data dimulai dari Januari 2006 hingga April 2018. Set data yang digunakan merupakan level bulanan sebanyak 148 observasi. 


\subsection{Tahapan Penelitian}

Langkah-langkah dalam penelitian ini mencakup:

1. Persiapan data, terdiri dari:

a. Pemeriksaan data untuk melihat apakah terdapat data hilang (missing) atau tidak, dan

b. Pembagian data menjadi data training dan data testing.

2. Pembentukan model peramalan dengan Resilient Back-propagation (Rprop) Neural Network, dengan tahapan:

a. Penentuan parameter, seperti jumlah hidden nodes, fungsi aktivasi/transfer yang akan digunakan, dan sebagainya.

b. Proses pelatihan jaringan syaraf tiruan (Neural Network Training) menggunakan data training dan parameter-parameter yang sudah ditetapkan sebelumnya.

c. Pemilihan parameter yang menghasilkan nilai MAPE terkecil.

d. Pembentukan model peramalan dengan nilai parameter terpilih.

3. Peramalan menggunakan model yang dibentuk pada tahap sebelumnya.

4. Uji performa (validasi) hasil peramalan dengan menggunakan nilai MAPE.

\section{Hasil dan Pembahasan}

\subsection{Persiapan Data}

Penelitian ini menggunakan tujuh variabel prediktor, dimana enam diantaranya merupakan variabel kategorik. Penjelasan mengenai variabel prediktor dapat dilihat pada tabel dibawah:

Tabel 1. Variabel Prediktor

\begin{tabular}{|c|c|c|}
\hline No & $\begin{array}{c}\text { Variabel } \\
\text { Prediktor }\end{array}$ & Kategorisasi \\
\hline \multirow{4}{*}{1} & & $1:$ umur 15-19 \\
\cline { 3 - 3 } & \multirow{4}{*}{ Umur } & 2: umur 20-24 \\
\cline { 3 - 3 } & & $3:$ umur 25-29 \\
\cline { 3 - 3 } & & $4:$ umur 30-34 \\
\cline { 3 - 3 } & & $5:$ umur 35-39 \\
\cline { 3 - 3 } & & 6: umur 40-44 \\
\cline { 3 - 3 } 2 & \multirow{3}{*}{$\begin{array}{c}\text { umur kawin } \\
\text { pertama }\end{array}$} & 1: umur 45-49 \\
\cline { 3 - 3 } & & 2: umur 20-24 \\
\cline { 3 - 3 } & & $3:$ umur 25-29 \\
\hline
\end{tabular}

\begin{tabular}{|c|c|c|}
\hline & & 4: umur 30-34 \\
\hline & & 5: umur 35-39 \\
\hline & & 6: umur 40-44 \\
\hline & & 7: umur 45-49 \\
\hline \multirow{2}{*}{3} & \multirow{2}{*}{$\begin{array}{c}\text { status } \\
\text { pekerjaan }\end{array}$} & 1: bekerja \\
\hline & & 2: tidak bekerja \\
\hline 4 & jumlah anak & Data kontinyu \\
\hline \multirow{2}{*}{5} & \multirow{2}{*}{$\begin{array}{l}\text { jaminan } \\
\text { kesehatan }\end{array}$} & 1: memiliki \\
\hline & & 2: tidak memiliki \\
\hline \multirow{5}{*}{6} & \multirow{5}{*}{$\begin{array}{c}\text { ijazah } \\
\text { terakhir yang } \\
\text { dimiliki }\end{array}$} & 1: tidak punya ijazah \\
\hline & & 2: sekolah dasar \\
\hline & & $\begin{array}{c}\text { 3: sekolah lanjutan } \\
\text { pertama }\end{array}$ \\
\hline & & 4: sekolah lanjutan atas \\
\hline & & 5: pendidikan tinggi \\
\hline \multirow{6}{*}{7} & \multirow{6}{*}{$\begin{array}{l}\text { pengeluaran } \\
\text { perkapita }\end{array}$} & $1:<1.000 .000$ \\
\hline & & 2: $1.000 .001-2.000 .000$ \\
\hline & & 3: 2.000.001-3.000.000 \\
\hline & & 4: $3.000 .001-4.000 .000$ \\
\hline & & 5: 4.000.001-5.000.000 \\
\hline & & $6:>5.000 .000$ \\
\hline
\end{tabular}

Prosedur yang digunakan pada evaluasi klasifikasi pada penelitian ini adalah Apparent Error Rate (APER). Nilai APER menunjukkan proporsi kesalahan sampel klasifikasi oleh fungsi klasifikasi (Jhonson et al, 1992). Penjelasan mengenai konsep APER dapat lebih jelas diketahui melalui tabel error klasifikasi:

Tabel 2. Tabel error klasifikasi

\begin{tabular}{|c|c|c|}
\hline \multirow{2}{*}{ ACTUAL } & \multicolumn{2}{|c|}{ PREDICT } \\
\cline { 2 - 3 } & TRUE & FALSE \\
\hline TRUE & $n_{11}$ & $n_{12}$ \\
\hline FALSE & $n_{21}$ & $n_{22}$ \\
\hline
\end{tabular}

Dimana nilai APER adalah

$$
A P E R=\frac{n_{12}+n_{21}}{n_{11}+n_{12}+n_{21}+n_{22}}
$$

Nilai APER terendah akan digunakan untuk memmodelkan pemelihan penggunaan alat kontrasepsi.

Penelitian ini menggunakan Support Vector Machine dengan 75 persen dan 80 persen data training dengan empat jenis kernel yaitu kernel linier, polynomial, radial basis dan sigmoid. Data diolah dengan menggunakan software $\mathrm{r}$ dengan package e1071 

data:

Berikut ditampilkan hasil pengolahan

Tabel 3. Support Vector Machine dengan

\begin{tabular}{|c|c|c|c|c|}
\hline \multicolumn{5}{|c|}{ 1-APER tertinggi } \\
\hline \multicolumn{5}{|c|}{$75 \%$ Training Data } \\
\hline kernel & cost & Gamma & degree & $\begin{array}{c}1- \\
\text { APER }\end{array}$ \\
\hline Linear & 1 & 0.14286 & - & 68,55 \\
\hline Polynomial & 1 & 0.14286 & 3 & 70,79 \\
\hline Radial Basis & 1 & 0.14286 & - & 73,76 \\
\hline Sigmoid & 1 & 0.14286 & - & 55,32 \\
\hline \multicolumn{5}{|c|}{$80 \%$ Training Data } \\
\hline kernel & cost & Gamma & degree & $\begin{array}{c}1- \\
\text { APER } \\
\end{array}$ \\
\hline Linear & 1 & 0.14286 & - & 69,66 \\
\hline Polynomial & 1 & 0.14286 & 3 & 71,36 \\
\hline $\begin{array}{c}\text { Radial } \\
\text { Basis }\end{array}$ & 1 & 0.14286 & - & $\mathbf{7 3 , 8 3}$ \\
\hline Sigmoid & 1 & 0.14286 & - & 55,57 \\
\hline
\end{tabular}

Model terbaik yang didapatkan pada penelitian ini adalah dengan data training 80 persen, kernel radial basis dengan cost 1 dan gamma 0.14286. Nilai APER yang dihasilkan adalah senilai 26,17 persen. Nilai 1-APER yang sudah bernilai diatas 70 persen dapat menunjukkan bahwa model SVM sudah dapat menggambarkan pemilihan perempuan usia subur untuk menggunakan alat kontrasepsi atau tidak.

\section{Kesimpulan}

Support Vector Machine dapat menggambarkan keputusan wanita usia subur untuk menggunakan alat kontrasepsi atau tidak. Kernel terbaik pada penelitian ini adalah kernel radial basis dengan cost 1 dan gamma 0.14286

\section{Referensi}

[1] Tobing, M., Kolibu, F., Rumayar, A., Hubungan Antara Faktor-Faktor Yang Mempengaruhi Penggunaan KB di Wilayah Kerja Puskesmas Kapitu Kecamatan Amurang Barat, Jurnal Ilmiah Farmasi UNSRAT Vol.4 No 4 (2015)

[2] Departemen Kesehatan RI. Buletin Jendela Data dan Informasi Kesehatan. Departemen Kesehatan RI (2013)

[3] www.beritamalukuonline.com/2015/04/ank a-kelahiran-di-malut-tinggi

[4] Kusumaningrum, R., Skripsi, Hubungan Antara Faktor-Faktor Yang Mempengaruhi Pemilihan Jenis Kontrasepsi Yang Digunakan Pada Pasangan Usia Subur, Universitas Diponogoro, Indonesia, 2009

[5] Lucas, D., Mc Donald, P., Young, E., Pengantar Kependudukan, Gajah Mada University Press (1990)

[6] Boser, B. E., Guyon, I. M., Vapnik, V. N., A Training Algorithm For Optimal Margin Classifiers. Proceedings of the fifth annual workshop on Computational Learning Theory - COLT'92.p.144

[7] N. Mussafi, "Analisis Risk Asset Portfolio Berbasis Reward To Variability Pada Saham Syariah Di Indonesia Menggunakan Nonlinear Programming", mantik, vol. 3, no. 2, pp. 57-64, Oct. 2017. 